\title{
Tricuspid regurgitation or Ebsteinoid dysplasia of the tricuspid valve in congenitally corrected transposition: Is valvuloplasty necessary at anatomic repair?
}

\author{
Patrick O. Myers, MD, ${ }^{\mathrm{a}, \mathrm{b}}$ Victor Bautista-Hernandez, MD, ${ }^{\mathrm{a}}$ Christopher W. Baird, MD, ${ }^{\mathrm{a}}$ \\ Sitaram M. Emani, MD, ${ }^{a}$ Gerald R. Marx, MD, ${ }^{c}$ and Pedro J. del Nido, MD ${ }^{\mathrm{a}}$
}

\begin{abstract}
Objectives: Patients with congenitally corrected transposition of the great arteries can present with tricuspid regurgitation (TR) and Ebsteinoid dysplasia of the tricuspid valve. To determine the fate of the tricuspid valve after anatomic repair and the effectiveness of tricuspid valvuloplasty, we reviewed our experience with anatomic repair of congenitally corrected transposition of the great arteries.
\end{abstract}

\begin{abstract}
Methods: From 1992 to 2012, 106 patients with congenitally corrected transposition of the great arteries underwent anatomic repair. Of the 106 patients, $24(22.6 \%)$ had moderate or greater TR before anatomic repair, 14 of whom had Ebsteinoid dysplasia. Nine patients (8.5\%) had Ebsteinoid dysplasia without significant TR, and 73 patients $(68.9 \%)$ had neither TR nor dysplasia.

Results: Of the 106 patients, $6(5.6 \%)$ with TR underwent tricuspid valvuloplasty at anatomic repair, 5 with $(21 \%)$ and 1 without $(11 \%)$ Ebsteinoid dysplasia $(P<.001)$. During a median follow-up period of 32 months, of the 24 patients with TR before anatomic repair, all 6 who had undergone tricuspid valvuloplasty had mild TR or less at the latest follow-up visit; 15 of the $18(83 \%)$ without valvuloplasty had mild TR or less $(P=.4)$ and $3(16.7 \%)$ had moderate or greater TR. Of the 14 patients with Ebsteinoid dysplasia and TR, 5 underwent valvuloplasty and had no significant TR during follow-up; 2 of the $9(22.2 \%)$ without valvuloplasty had moderate or greater TR $(P=.51)$. Valvuloplasty was associated with an absolute risk of TR reduction of $16.7 \%$, which was further reduced by $22.2 \%$ in patients with associated Ebsteinoid dysplasia.
\end{abstract}

Conclusions: Tricuspid valve function significantly improved after anatomic repair, independent of direct surgical intervention. For significant TR associated with Ebsteinoid dysplasia, valvuloplasty should be considered. (J Thorac Cardiovasc Surg 2014;147:576-80)

Congenitally corrected transposition of the great arteries (ccTGA), although rare and representing $<1 \%$ of all congenital heart defects, ${ }^{1}$ is often associated with tricuspid regurgitation (TR), with or without dysplasia of the tricuspid valve that mimics the tricuspid valve dysplasia seen in Ebstein's anomaly. ${ }^{2}$ TR is an integral part of the natural history of this anatomy owing to functional tricuspid valve dysfunction, because it is associated with right ventricular (RV) dysfunction. It will improve when the left ventricular (LV) and RV pressures are equalized or

From the Department of Cardiac Surgery, ${ }^{\text {a }}$ Boston Children's Hospital, Harvard Medical School, Boston, Mass; Department of Cardiovascular Surgery, ${ }^{\mathrm{b}}$ Geneva University Hospitals and School of Medicine, Geneva, Switzerland; and Department of Cardiology, ${ }^{\mathrm{c}}$ Boston Children's Hospital, Harvard Medical School, Boston, Mass.

Disclosures: Authors have nothing to disclose with regard to commercial support.

Presented at The American Association for Thoracic Surgery Mitral Conclave 2013, New York, NY, May 2, 2013.

Received for publication May 4, 2013; revisions received July 28, 2013; accepted for publication Oct 6, 2013; available ahead of print Nov 22, 2013.

Address for reprints: Pedro J. del Nido, MD, Department of Cardiac Surgery, Boston Children's Hospital, Harvard Medical School, 300 Longwood Ave, Bader 273, Boston, MA 02115 (E-mail: pedro.delnido@ childrens.harvard.edu). 0022-5223/\$36.00

Copyright (c) 2014 by The American Association for Thoracic Surgery http://dx.doi.org/10.1016/j.jtcvs.2013.10.014 inversed and the ventricular septum shifts, such as after pulmonary artery banding for LV preparation ${ }^{3,4}$ or anatomic repair, ${ }^{5}$ placing the tricuspid valve as the low-pressure, subpulmonary atrioventricular valve.

Ebsteinoid dysplasia of the tricuspid valve in ccTGA represents a variable spectrum of disease, with failure of delamination of the tricuspid valve leaflets from the RV wall and subsequent tethering and apical displacement of the leaflet hinge points, maximally at the commissure between the posterior and septal leaflets. ${ }^{6}$ We have preferred the term "Ebsteinoid dysplasia" for this lesion, because significant differences exist between it and Ebstein's anomaly ${ }^{7}$ with a concordant atrioventricular connection compared with the tricuspid dysplasia seen in atrioventricular discordance: The atrialized portion of the right ventricle is not thinned, rarely the mural or septal leaflet can be absent, and it has been associated with a ventricular septal defect ${ }^{6}$ and aortic arch obstruction. ${ }^{8}$

Physiologic repair of ccTGA, in which the right ventricle is left in the systemic position, and associated anomalies, such as TR, ventricular septal defect, and pulmonary atresia, are repaired, carries a high risk, and patients are often referred late for surgical repair, when the systemic $\mathrm{RV}$ function has started to decline. ${ }^{9}$ In this setting, repair 


\section{Abbreviations and Acronyms \\ ccTGA $=$ Congenitally corrected transposition of the great arteries \\ $\mathrm{LV}=$ left ventricular \\ $\mathrm{mRV}=$ morphologic right ventricle \\ $\mathrm{RV} \quad=$ right ventricular \\ $\mathrm{TR}=$ tricuspid regurgitation}

has provided poor results, given that the tricuspid valve supports the systemic circulation, and valve replacement has been advocated, ${ }^{10}$ albeit at a high operative risk. Anatomic repair, which corrects atrioventricular and ventriculoarterial discordance using a double-switch procedure, places the right ventricle and tricuspid valve in the pulmonary position. It is a promising solution that has shown low operative mortality and good functional results compared with physiologic repair., ${ }^{11-14}$

Murtuza and colleagues ${ }^{14}$ reported, among 113 patients who had undergone anatomic repair, a prevalence of Ebsteinoid dysplasia of the tricuspid valve of $12.3 \%(n=14)$, and 6 patients $(5.3 \%)$ had severe TR. Currently, little information is available regarding the best management of significant TR, in particular, when associated with Ebsteinoid dysplasia at anatomic repair of ccTGA. The goal of the present study was to review our experience in managing the tricuspid valve in patients with significant TR at anatomic repair and infer the best surgical option for treatment.

\section{METHODS}

\section{Study Design}

The present study was a retrospective review of all patients with ccTGA who had undergone anatomic repair at our institution from 1992 to 2012. The Boston Children's Hospital institutional review board approved the present study, and individual patient consent was waived.

The primary endpoints were moderate or greater TR and tricuspid valve reoperation after anatomic repair. The clinical and treatment variables were recorded to determine the predictors of the endpoints. All patients underwent follow-up examination to death or June 2012.

\section{Surgical Technique}

The surgical techniques used in the present study population have been previously reported in detail. ${ }^{15}$ The decision to address the tricuspid valve at anatomic repair was determined from the preoperative echocardiographic findings of the presence of moderate or greater TR and a discernable structural defect, such as a tethered septal leaflet, cleft, or splayed-open anteroseptal commissure. The surgical techniques were tailored to the mechanism responsible for regurgitation at the discretion of the operating surgeon. Exposing the tricuspid valve can be challenging in patients with ccTGA and mesocardia, because the ventricular mass lies anterior to the atrial mass. In these patients, we rotate the ventricular mass into the left pleural space in situs solitus or the right pleural space in situs inversus to expose the tricuspid valve.

\section{Statistical Analysis}

Statistical analyses were performed using the Statistical Package for Social Sciences software, version 21 (SPSS, Inc, Chicago, Ill). The data are presented as mean \pm standard deviation or median and range, as appropriate. Continuous variables were analyzed using the related samples Wilcoxon signed rank test or the Kruskal-Wallis 1-way analysis of variance test, and categorical variables using the chi-square test or Fisher's exact test. All statistical tests were 2-tailed, and $P<.05$ was considered significant.

\section{RESULTS}

\section{Study Population}

The study population has previously been described in detail. ${ }^{16} \mathrm{~A}$ total of 106 consecutive patients underwent anatomic repair for ccTGA during the study period. The median age at surgery was 1.2 years (range, 2 months to 43 years). The segmental anatomy was SLL (situs solitus, L-loop ventricles, L-transposed great arteries) in 93 patients $(87.7 \%)$ and IDD (situs inversus, D-loop ventricules, D-transposed great arteries) in 13 patients $(12.3 \%)$. Levocardia was present in 63 patients $(59.4 \%)$, dextrocardia in $24(22.6 \%)$, and mesocardia in $9(8.5 \%)$. Atrial switch was accomplished using a modified Senning procedure in 35 patients $(33 \%)$ and a Mustard procedure in $71(67 \%)$. Also, 42 patients $(39.6 \%)$ had undergone a Rastelli procedure for $\mathrm{LV}$ outflow reconstruction and $62(58.5 \%)$ arterial switch for restoration of the ventriculoarterial concordance. Two patients $(1.9 \%)$ had undergone a Nikaidoh procedure late in our experience.

A detailed breakdown of the patient subgoups and outcomes are summarized in Figure 1. Of the 106 patients, $24(22.6 \%)$ had moderate or severe TR before anatomic repair, 15 of whom had Ebsteinoid dysplasia of the tricuspid valve. Another 9 patients $(8.5 \%)$ had Ebsteinoid dysplasia without significant TR, and 73 patients $(68.9 \%)$ had neither TR nor dysplasia and were used as controls. Of the patients with TR, $9(37.5 \%)$ had previously undergone pulmonary artery banding, and 15 of the controls had also $(20.5 \% ; P=.08)$. The patient baseline characteristics are summarized in Table 1. More patients with significant TR and/or Ebsteinoid dysplasia had undergone arterial switch (29 of 35) than a Rastelli procedure (6 of $35 ; P=.007$ ).

\section{Tricuspid Valvuloplasty at Anatomic Repair}

Six patients $(5.6 \%$, all in the TR group) had undergone tricuspid valvuloplasty at anatomic repair, 5 with Ebsteinoid dysplasia $(20.8 \%)$ and 1 without Ebsteinoid dysplasia $(11.1 \% ; P<.001)$. The repair techniques consisted predominantly of anteroseptal commissure closure and suture annuloplasty (Table 2). The predominant lesion responsible for regurgitation found on tricuspid valve inspection was a cleft on the septal leaflet or a splayed-open anteroseptal commissure, with thickened and rolled edges from TR. This was addressed by cleft closure, closure of the regurgitant anteroseptal commissure and/or partial suture annuloplasty, annulus plication, or commissuroplasty. All 6 patients who had undergone valvuloplasty 


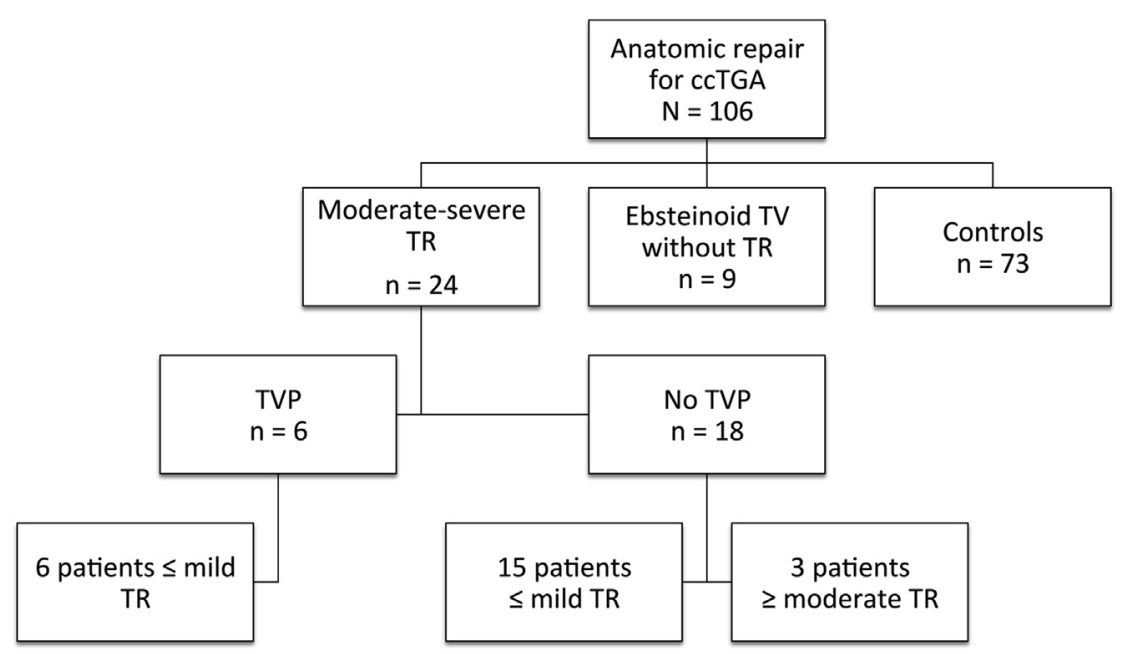

FIGURE 1. Flowchart of patient subgroups and outcomes. $c c T G A$, Congenitally corrected transposition of the great arteries; $T R$, tricuspid valve regurgitation; $T V$, tricuspid valve; $T V P$, tricuspid valvuloplasty.

had also undergone arterial switch, and none had undergone a Rastelli or Nikaidoh procedure.

\section{Outcomes After Anatomic Repair}

Of the 106 patients, 6 died early (5.7\%) and 3 died late during a median follow-up of 32 months (range, 7 days to 7.2 years) after anatomic repair. Stratified by group, 1 early death occurred in the TR group $(4.2 \%)$, none in the Ebsteinoid dysplasia group, and 5 in the control group $(6.8 \%, P>.99)$. Overall, 2 patients in the TR group died

TABLE 1. Patient baseline and operative characteristics

\begin{tabular}{lcccc}
\hline \multicolumn{1}{c}{ Variable } & TR & $\begin{array}{c}\text { Ebsteinoid } \\
\text { dysplasia }\end{array}$ & Controls & $\begin{array}{c}\boldsymbol{P} \\
\text { value }\end{array}$ \\
\hline Patients (n) & 24 & 9 & 73 & \\
Age (y) & $1.1(0.2-39.6)$ & $1.6(0.4-9.6)$ & $1.2(0.2-43)$ & .98 \\
Weight (kg) & $9.4(4-67)$ & $8.6(4-40)$ & $9.7(3-66)$ & .98 \\
Segmental anatomy & & & & \\
$\quad$ SLL & $23(95.8)$ & $9(100)$ & $61(83.6)$ & .19 \\
IDD & $1(4.2)$ & $0(0)$ & $12(16.4)$ & .19 \\
Associated anomalies & & & & \\
$\quad$ VSD & $19(79.2)$ & $6(66.7)$ & $68(93.2)$ & .02 \\
Pulmonary stenosis & $9(37.5)$ & $1(11.1)$ & $32(43.8)$ & .15 \\
Pulmonary atresia & $2(8.3)$ & $2(22.2)$ & $27(37)$ & .02 \\
Ebsteinoid dysplasia & $14(58.3)$ & $9(100)$ & $0(0)$ & $<.001$ \\
$\quad$ Moderate or more TR & $24(100)$ & $0(0)$ & $0(0)$ & $<.001$ \\
Previous PA band & $9(37.5)$ & $6(66.7)$ & $15(20.5)$ & .009 \\
Atrial switch & & & & .60 \\
$\quad$ Modified Senning & $10(41.7)$ & $3(33.3)$ & $22(30.1)$ & \\
$\quad$ Mustard & $14(58.3)$ & $6(66.7)$ & $51(69.9)$ & \\
Arterial switch & & & & .007 \\
$\quad$ Arterial switch & $21(87.5)$ & $6(66.7)$ & $35(47.9)$ & \\
Rastelli & $3(12.5)$ & $3(33.3)$ & $36(49.3)$ & \\
Nikaidoh & $2(2.7)$ & $0(0)$ & $0(0)$ & \\
\hline Data & & &
\end{tabular}

Data presented as median (range) or n (\%). TR, Tricuspid regurgitation; $S L L$, situs solitus, L-loop ventricles, L-transposed great arteries; IDD, situs inversus, D-loop ventricules, D-transposed great arteries; VSD, ventricular septal defect; $P A$, pulmonary artery.
$(8.3 \%)$, none in the Ebsteinoid dysplasia group, and 7 in the control group $(9.6 \%, P>.99)$.

Of the 24 patients with significant TR before anatomic repair, all 6 patients who had undergone tricuspid valvuloplasty had mild or less TR at the latest followup visit. Of the 18 patients who did not have the tricuspid valve addressed, $15(83 \%)$ had mild or less TR and $3(17 \%)$, with preoperative significant TR, had moderate or severe TR $(P=.4)$, all with an Ebsteinoid tricuspid valve.

The outcomes of patients with Ebsteinoid dysplasia are summarized in Figure 2. Of the 23 patients with Ebsteinoid dysplasia of the tricuspid valve (with or without significant TR before anatomic repair), all 5 patients who had undergone valvuloplasty had mild or less TR at the latest follow-up examination, and 3 of the 18 without valvuloplasty $(16.7 \%)$ had moderate or more TR $(P=.46)$. Of the 14 patients with Ebsteinoid dysplasia and TR, 5 had undergone valvuloplasty and had no significant TR during the follow-up period, and 2 of 9 without valvuloplasty $(22.2 \%)$ had moderate or more TR $(P=.51)$. In summary, although these differences between patients with and without valvuloplasty were not statistically significant, in patients with TR or Ebsteinoid dysplasia, valvuloplasty resulted in an absolute risk reduction of TR of $16.7 \%$. This absolute risk reduction of TR by valvuloplasty was increased further to $22.2 \%$ in

TABLE 2. Tricuspid valvuloplasty techniques at anatomic repair

\begin{tabular}{lc}
\hline \multicolumn{1}{c}{ Technique } & Patients (n) \\
\hline Anteroseptal commissure closure & 3 \\
Annulus plication & 1 \\
Suture annuloplasty & 1 \\
Commissuroplasty & 1 \\
Cleft closure & 1 \\
Supravalvar ring resection & 1 \\
\hline
\end{tabular}

Two patients had $>1$ tricuspid valvuloplasty technique used. 


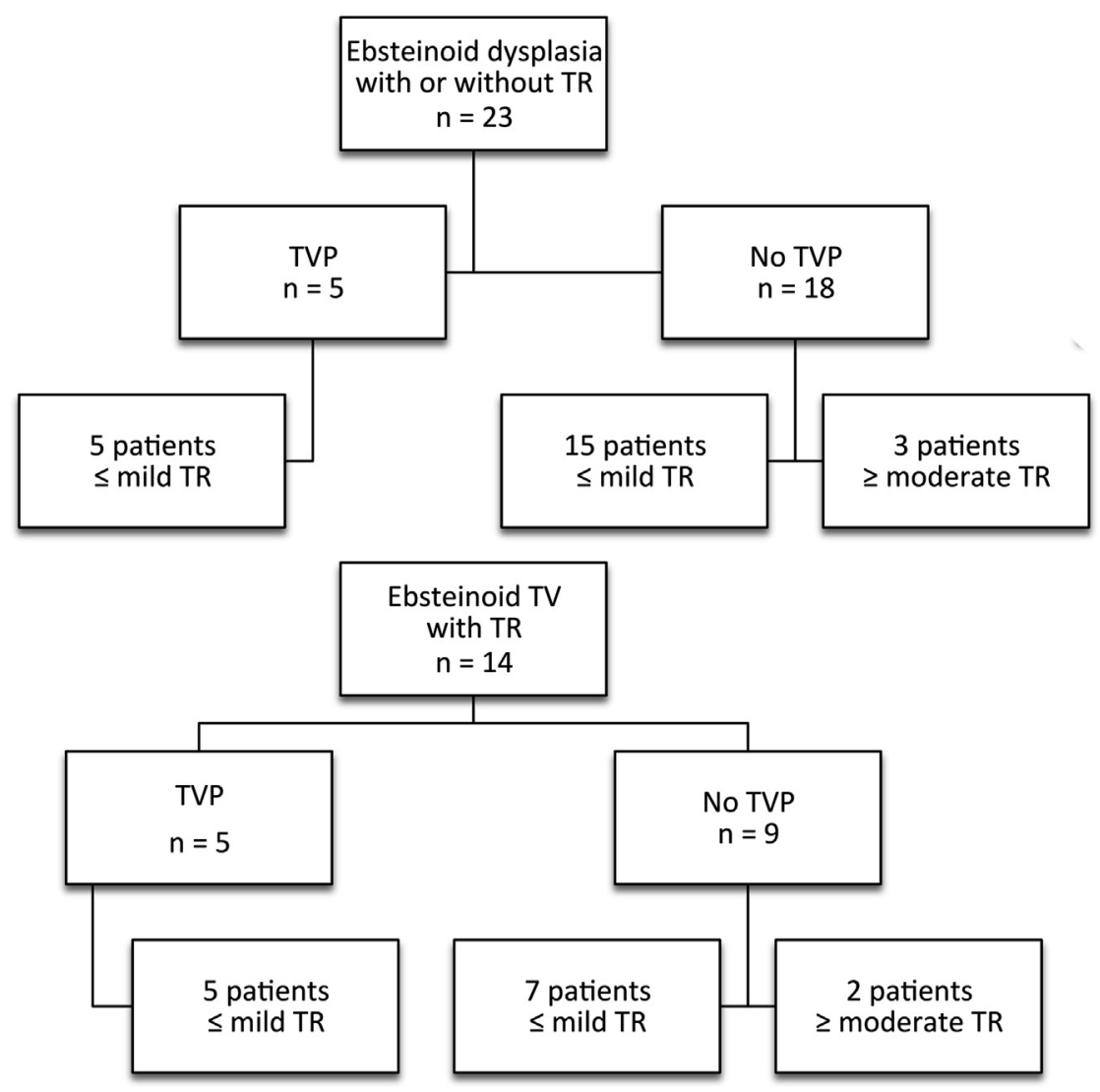

FIGURE 2. Flowchart of patients with Ebsteinoid tricuspid valve. $T R$, Tricuspid valve regurgitation; TVP, tricuspid valvuloplasty.

patients with Ebsteinoid dysplasia with significant TR before anatomic repair.

\section{DISCUSSION}

Physiologic repair of ccTGA that addresses the associated lesions, such as ventricular septal defects, TR, or pulmonary artery stenosis or atresia, leaves the morphologic right ventricle (mRV) to support the systemic circulation. This has resulted in documented deteriorating $\mathrm{mRV}$ function, TR, and survival at 1 year of $84 \%$, with a decline to $60 \%$ at 15 years. ${ }^{17,18}$ Anatomic repair, or the so-called double switch, restores the morphologic left ventricle to the systemic circulation. Clinical series have suggested that anatomic repair is associated with low operative mortality and superior survival and New York Heart Association functional class. ${ }^{1,11-14}$

There is considerable debate, however, regarding the optimal management of Ebsteinoid dysplasia of the tricuspid valve and/or TR at anatomic repair. Restoring the $\mathrm{mRV}$ to the low-pressure pulmonary circulation has been shown to markedly reduce TR just by virtue of mechanical unloading of the $\mathrm{mRV}$ and septal shift with restoration of the morphologic left ventricle to the systemic circulation. $^{19,20}$ In our experience, the TR improved significantly after anatomic repair, even without tricuspid valvuloplasty. Only 3 of 18 patients with significant TR before anatomic repair who did not undergo valvuloplasty and 2 of 9 patients with significant TR and Ebsteinoid dysplasia who did not undergo valvuloplasty had significant TR during the follow-up period. Furthermore, this decision will be complicated further because a proportion of patients with Ebstenoid dysplasia of the tricuspid valve ( 9 patients in our series, representing $8.5 \%$ of our ccTGA population and $37.5 \%$ of our patients with Ebsteinoid dysplasia) will have mild to no TR before anatomic repair. As the results of anatomic repair improve and enthusiasm for this approach to ccTGA increases, prompting earlier referral and surgical management to avoid mRV dysfunction, the landscape of tricuspid valve function before anatomic repair could also improve, and the questions regarding Ebsteinoid dysplasia and mild to moderate TR could become even more important.

However, these patients are relatively rare, and few data exist to guide the management of the tricuspid valve in these patients. In the largest series reported of anatomic repair for ccTGA, Murtuza and colleagues ${ }^{14}$ reported a prevalence of $12.3 \%$ (14 of 113) for Ebsteinoid dysplasia and a prevalence of $5.3 \%$ (6 of 113) for severe TR before anatomic repair. Although not formally included in their extensive report, 15 of their patients $(13.2 \%)$ had 
undergone tricuspid valvuloplasty at anatomic repair. Their reported strategy was to examine the tricuspid valve in all patients at anatomic repair, and only those in whom a gap or cleft in the valve was evident underwent repair. With this approach, 3 patients $(2.7 \%)$ required reoperation for tricuspid valve repeat repair, and 40 patients $(35.4 \%$; data not reported but calculated from discussion) presented with mild to moderate $\mathrm{TR}$ after anatomic repair.

From these and our data, it appears that simple valve repair techniques, far from the complexity of cone reconstruction of the tricuspid valve, ${ }^{21}$ which can be technically difficult with the left-sided tricuspid valve in ccTGA and frequent dextrocardia or mesocardia, is sufficient to ensure a reasonable result and that valvuloplasty has an important role in reducing the risk of TR after anatomic repair.

The present study had several limitations. First, it was a retrospective, noninterventional study designed to evaluate the outcomes of an established clinical program. All patients were treated as individuals and not according to a treatment protocol, which would have improved our ability to analyze the outcomes. Our analyses were limited by the limited patient sample, although representing one of the largest populations of anatomic repairs. Nonetheless, the present study was the first to look into the impact of tricuspid valve function at anatomic repair and tricuspid valve repair techniques, along with tricuspid regurgitation and Ebsteinoid dysplasia before anatomic repair in ccTGA.

\section{CONCLUSIONS}

TR and Ebsteinoid dysplasia of the tricuspid valve are common in patients with ccTGA. Tricuspid valve function improved significantly after anatomic repair in all groups. Simple repair techniques were sufficient to avoid significant $\mathrm{TR}$ at mid-term follow-up and tended to afford a reduction in the absolute risk of TR of $16 \%$ to $22 \%$ in patients with TR and/or Ebsteinoid dysplasia.

\section{References}

1. Bautista-Hernandez V, Marx GR, Gauvreau K, Mayer JE, Cecchin F, Del Nido PJ. Determinants of left ventricular dysfunction after anatomic repair of congenitally corrected transposition of the great arteries. Ann Thorac Surg. 2006;82:2059-65.

2. Anderson KR, Danielson GK, McGoon DC, Lie JT. Ebstein's anomaly of the left-sided tricuspid valve: pathological anatomy of the valvular malformation. Circulation. 1978;58(3 Pt 2):I87-91.

3. Quinn DW, McGuirk SP, Metha C, Nightingale P, De Giovanni JV, Dhillon R, et al. The morphologic left ventricle that requires training by means of pulmonary artery banding before the double-switch procedure for congenitally corrected transposition of the great arteries is at risk of late dysfunction. J Thorac Cardiovasc Surg. 2008;135:1137-44.
4. Winlaw DS, McGuirk SP, Balmer C, Langley SM, Griselli M, Stumper O, et al. Intention-to-treat analysis of pulmonary artery banding in conditions with a morphological right ventricle in the systemic circulation with a view to anatomic biventricular repair. Circulation. 2005;111:405-11.

5. Myers PO, Del Nido PJ, Geva T, Bautista-Hernandez V, Chen P, Mayer JE, et al. Impact of age and duration of banding on left ventricular preparation before anatomic repair for congenitally corrected transposition of the great arteries. Ann Thorac Surg. 2013;96:603-10.

6. Silverman NH, Gerlis LM, Horowitz ES, Ho SY, Neches WH, Anderson RH. Pathologic elucidation of the echocardiographic features of Ebstein's malformation of the morphologically tricuspid valve in discordant atrioventricular connections. Am J Cardiol. 1995;76:1277-83.

7. van Son JA, Konstantinov IE, Zimmermann V. Wilhelm Ebstein and Ebstein's malformation. Eur J Cardiothorac Surg. 2001;20:1082-5.

8. Celermajer D, Cullen S. Congenitally corrected transposition and Ebstein's anomaly of the systemic atrioventricular valve: association with aortic arch obstruction. J Am Coll Cardiol. 1991;18:1056-8.

9. Mongeon F-P, Connolly HM, Dearani JA, Li Z, Warnes CA. Congenitally corrected transposition of the great arteries ventricular function at the time of systemic atrioventricular valve replacement predicts long-term ventricular function. J Am Coll Cardiol. 2011;57:2008-17.

10. Scherptong RWC, Vliegen HW, Winter MM, Holman ER, Mulder JM, van der Wall EE, et al. Tricuspid valve surgery in adults with a dysfunctional systemic right ventricle: repair or replace? Circulation. 2009;119:1467-72.

11. Hosseinpour AR, Amanullah M, Ramnarine IR, Stümper O, Barron DJ, Brawn WJ. Combined atrial arterial switch operation (double switch) for hearts with Shone syndrome and pulmonary hypertension. J Thorac Cardiovasc Surg. 2006;131:471-3.

12. Duncan BW, Mee RBB, Mesia IC, Qureshi A, Rosenthal GL, Seshadri SG, et al. Results of the double switch operation for congenitally corrected transposition of the great arteries. Eur J Cardiothorac Surg. 2003;24:11-20.

13. Sharma R, Talwar S, Marwah A, Shah S, Maheshwari S, Suresh P, et al. Anatomic repair for congenitally corrected transposition of the great arteries. J Thorac Cardiovasc Surg. 2009;137:404-12.

14. Murtuza B, Barron DJ, Stumper O, Stickley J, Eaton D, Jones TJ, et al. Anatomic repair for congenitally corrected transposition of the great arteries: a single-institution 19-year experience. J Thorac Cardiovasc Surg. 2011;142: 1348-57.

15. Bautista-Hernandez V, del Nido PJ. Congenitally corrected transposition of the great arteries surgical treatment palliative operations. In: Kaiser L, Kron IL, Spray TL, eds. Mastery of Cardiothoracic Surgery. 2nd ed. Philadelphia: Lippincott Williams \& Wilkins; 2006:871-8.

16. Bautista-Hernandez V, Myers PO, Cecchin F, Marx GR, Del Nido PJ. Late left ventricular dysfunction after anatomic repair of congenitally corrected transposition of the great arteries. J Thorac Cardiovasc Surg. October 5, 2013 [Epub ahead of print].

17. Hraska V, Duncan BW, Mayer JE, Freed M, Del Nido PJ, Jonas RA. Long-term outcome of surgically treated patients with corrected transposition of the great arteries. J Thorac Cardiovasc Surg. 2005;129:182-91.

18. Graham TP, Bernard YD, Mellen BG, Celermajer D, Baumgartner H, Cetta F, et al. Long-term outcome in congenitally corrected transposition of the great arteries. J Am Coll Cardiol. 2000;36:255-61.

19. Langley SM, Winlaw DS, Stumper O, Dhillon R, De Giovanni JV, Wright JG, et al. Midterm results after restoration of the morphologically left ventricle to the systemic circulation in patients with congenitally corrected transposition of the great arteries. J Thorac Cardiovasc Surg. 2003; 125:1229-40.

20. Hraška V, Mattes A, Haun C, Blaschczok HC, Photiadis J, Murin P, et al. Functional outcome of anatomic correction of corrected transposition of the great arteries. Eur J Cardiothorac Surg. 2011;40:1227-34.

21. Da Silva J, Baumgratz J, Da Fonseca L, Meiken Franchi S, Lopes L, Tavares G, et al. The cone reconstruction of the tricuspid valve in Ebstein's anomaly: the operation: early and midterm results. J Thorac Cardiovasc Surg. 2007;133: 215-23. 